\title{
$\operatorname{CONF-970638-1}$
}

\section{Eléctrical Characterization and Application of Very High Speed Vertical Cavity Surface Emitting Lasers (VCSELs)}

\section{M. Hietala, K. L. Lear, M. G. Armendariz, C. P. Tigges, H. Q. Hou, and J. C. Zolper PECENED \\ Sandia National Laboratories Albuquerque, NM 87185-0874

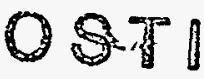

\section{ABSTRACT}

Vertical Cavity Surface Emitting Lasers (VCSELs) offer many benefits over conventional edgeemitting lasers including economical microelectronic batch processing, easy extension to 2-D arrays, and of interest here, very large intrinsic bandwidths due to reduced cavity volume. Results of electrical characterization of a $19 \mathrm{GHz}$ bandwidth $850 \mathrm{~nm}$ VCSEL are presented. Small-signal characterization and modeling of the frequency response and device impedance is presented. Large signal performance is studied using two-tone RF and high-speed digital measurements. Appropriate drive conditions for high-speed digital applications are demonstrated.

\section{INTRODUCTION}

Very high efficiency VCSELs with over $20 \mathrm{GHz}$ electrical bandwidths have been demonstrated with several $\mathrm{mW}$ output power. These are believed to be the fastest laser diodes ever realized at $850 \mathrm{~nm}$. Though this wavelength is not consistent with long-haul optical link needs, it is consistent with the Fibre Channel and ATM Forum standards and is in strong favor for economical short haul fiber optic links.

The small cavity volume of VCSELs allows for very large intrinsic bandwidths. By the careful minimization of electrical parasitics, we have successfully demonstrated VCSELs with bandwidths in excess of $20 \mathrm{GHz}$. [1] This has been achieved by using several novel process enhancements. Intrinsic device limits appear to be well in excess of $50 \mathrm{GHz}$. It appears that the present bandwidth is limited predominantly by thermal issues.

\section{DEVICE STRUCTURE}

A schematic diagram of the cross section of the high speed VCSEL is shown in Fig. 1. The VCSEL cavity is formed by MOVPE growth where an active region is appropriately positioned between two dielectric mirror stacks. The active region is comprised of five GaAs quantum wells. The mirrors are necessarily comprised of alternating layers of high and low Al fraction AlGaAs for high optical reflectivity. This need typically results in an undesirably high mirror resistance (due to heterojunction barriers) which significantly degrades device performance. To minimize this effect, a novel uniparabolic grading profile produced by MOVPE growth as well as careful doping considerations were used to greatly reduce the mirror resistance [2] To further minimize mirror resistance, the VCSEL was grown n-type up (see Fig. 1) to take advantage of the lower lateral resistance of the n-type material.

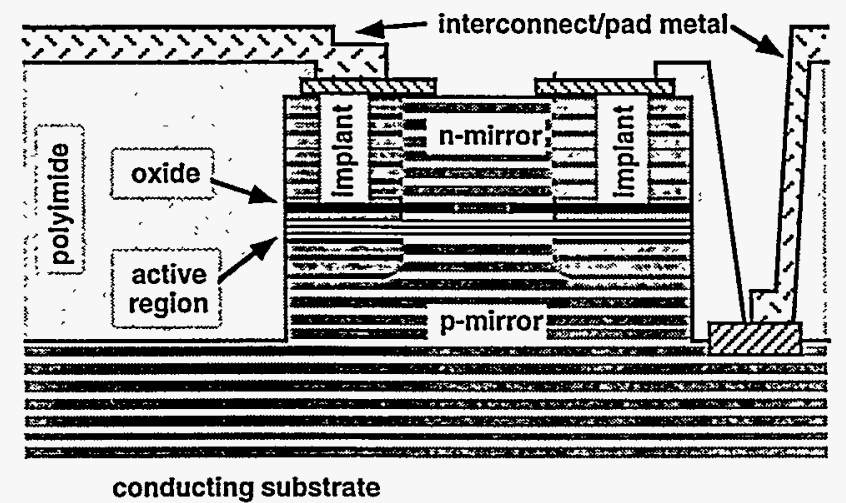

Fig. 1. Diagram of the VCSEL's cross section.

Another unique feature of these VCSELs is the use of a selective wet thermal oxidation used to convert an $\mathrm{AlGaAs}$ mirror layer to an insulating low index alumina film.[3] The low index of the resulting alumina layer yields excellent lateral 


\section{DISCLAIMER}

This report was prepared as an account of work sponsored by an agency of the United States Government. Neither the United States Government nor any agency thereof, nor any of their employees, make any warranty, express or implied, or assumes any legal liability or responsibility for the accuracy, completeness, or usefulness of any information, apparatus, product, or process disclosed, or represents that its use would not infringe privately owned rights. Reference herein to any specific commercial product, process, or service by trade name, trademark, manufacturer, or otherwise does not necessarily constitute or imply its endorsement, recommendation, or favoring by the United States Government or any agency thereof. The views and opinions of authors expressed herein do not necessarily state or reflect those of the United States Government or any agency thereof. 


\section{DISCLAIMER}

Portions of this document may be illegible in electronic image products. Images are produced from the best available original document. 
mode confinement and overlap with the electriical pump; and lasers with $50 \%$ power efficiency haave been demonstrated. [4]

Shown in Fig. 2 is a microphotograph of an acctual $4 \times 4 \mu \mathrm{m}^{2}$ device. Contact to the device is achieved by coplanar contacts. These contact pads are fabricated on top of a $4 \mu \mathrm{m}$ thick polyimide laayer which results in a low pad capacitance of about 50 $\mathrm{fF}$. To further reduce the total device capacitance, a proton implant was performed under the comtact regions (see Fig.1).

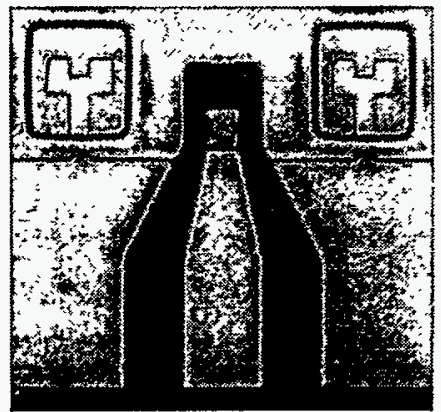

Fig. 2. Microphotograph of high-speed VCSEL. The VCSEL's $4 \times 4 \mu \mathrm{m}^{2}$ aperture is the small dot' seen at the end of the center strip.

All of the measurements in this paper wrere performed on-wafer using a standard RF prcobe and a lensed multimode fiber positioned normail to the DUT by using a Cascade Microtech lightweave probe. The light was detected using a $25 \mathrm{GHHz}$ bandwidth model 1431 New Focus detector.

Fig. 3 shows plots of the light in the friber (estimated based on the detector's responsirvity specification) and voltage for a 0 to $6 \mathrm{~mA}$ current bias range. Note the very low threshold curreent $(\approx 0.5 \mathrm{~mA})$ and the low operating voltage.

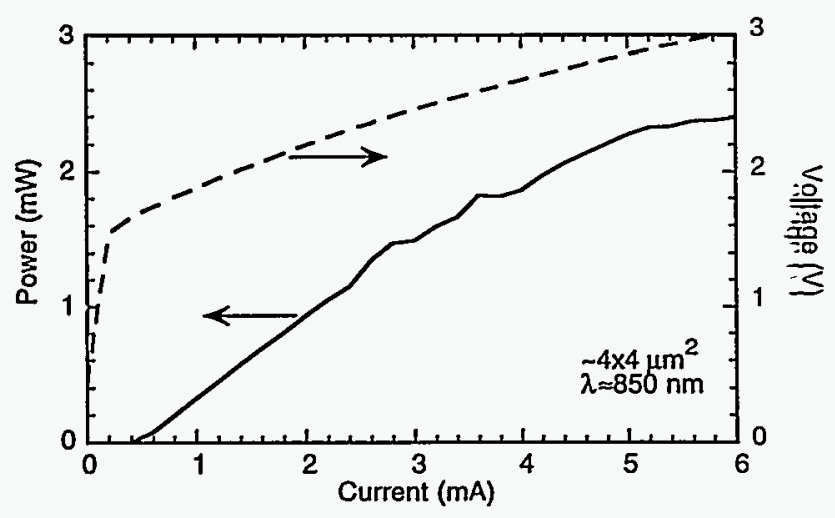

Fig. 3. Light (in fiber) and voltage over bias current.

\section{SMALL-SIGNAL MODEL}

Small-signal characterization was performed with an HP 8510 network analyzer using an LRM calibration for the impedance measurements and a simple response calibration along with correction for probe loss and detector response for the response measurements.

Plotted in Fig. 4 is the measured SII for several different bias currents. Due to the small size of these VCSELs and the mirror resistamce, electrical drive impedances are much higher than with conventional edge emitter lasers.

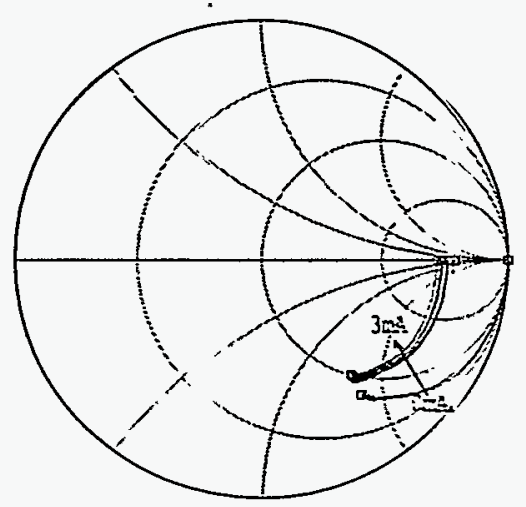

Fig. 4. Measured S1I of the VCSEL at $0,1,2$, and $3 \mathrm{~mA}$ bias currents ( 0.045 to $25 \mathrm{GHz}$ ).

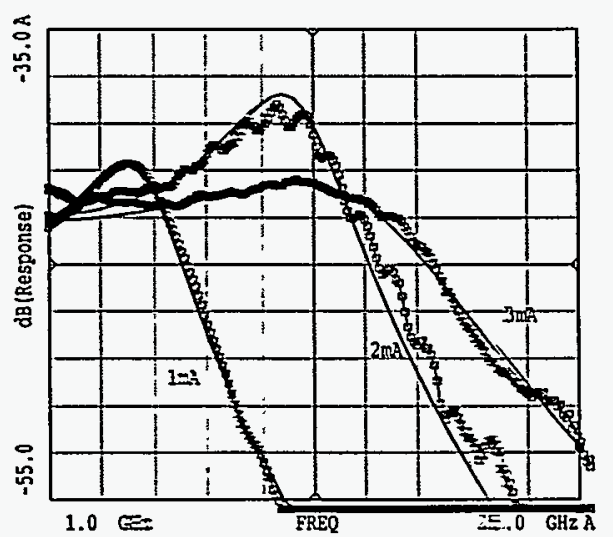

Fig. 5. Modulation response of a tigh speed VCSEL exhibiting a $19 \mathrm{GHz}-3 \mathrm{~dB}$ frequency. Curves are for 1,2 and $3 \mathrm{~mA}$ bias as labeled.

Fig. 5 shows the measured response along with corresponding fits using the small-signal model outlined in Fig. 6. A co-optimization was used to simultaneously fit the measured $S 11$ and response. In general, the modeled S11 results (mot shown in 
Fig. 4 for clarity) were very similar to the measured. From a co-optimization at several bias conditions $C_{p}=54 \mathrm{fF}, \mathrm{R}_{\mathrm{p}}=16 \Omega$, and $\mathrm{R}_{\mathrm{m}}=136 \Omega$. The active region's equivalent capacitance, $\mathrm{C}_{\mathrm{a}}$ and equivalent resistance, $R_{a}$ were found to be bias dependent with $R_{\text {a }}$ varying from $270 \Omega$ at $1 \mathrm{~mA}$ to $160 \Omega$ at $5 \mathrm{~mA}$ and $C_{\mathrm{a}}$ varying from $67 \mathrm{fF}$ at $1 \mathrm{~mA}$ to $106 \mathrm{fF}$ at $5 \mathrm{~mA}$. These values for $\mathrm{R}_{\mathrm{a}}$ may seem large as compared to a normal junction resistance, but this resistance includes a combination of lateral and spreading tẹms.

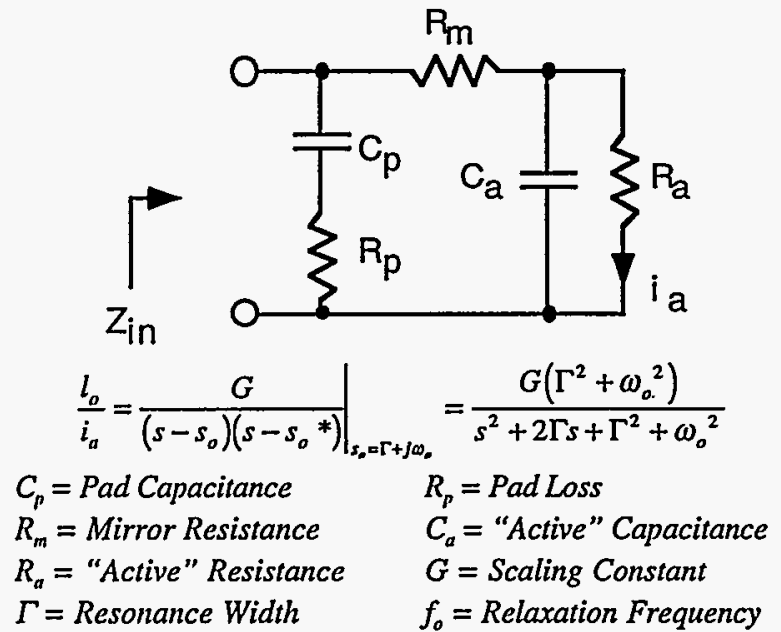

Fig. 6. Small-signal VCSEL equivalent circuit.

The differential light output, $l_{o}$, is modeled using the traditional damped resonator model.

Fig. 7 shows a plot of the measured cutoff frequency, $f_{-3 d B}$; the relaxation frequency, $f_{o}$; and the resonance width $\Gamma / 2 \pi$ (defined in Fig. 6) plotted against bias current. At low bias currents, from conventional rate equation analysis, the $3 \mathrm{~dB}$ bandwidth is known to increase in proportion to the square root the drive current above threshold. For the data in Fig. 7, the resulting modulation current efficiency factor is about $15.2 \mathrm{GHz} / \sqrt{\mathrm{mA}}$. The resonant frequency, $f_{0}$, is seen to increase rapidly at low bias currents and then quickly saturate at about $3 \mathrm{~mA}$ to around $16 \mathrm{GHz}$. This is a clear indication of a limit due to heating in the device. A quadratic fit of the damping rate, $\Gamma$, against the resonant frequency, $f_{o}$, at resonant frequencies below $15 \mathrm{GHz}$, results in $\mathrm{K}$ factor of $95 \mathrm{pS}$ which implies an intrinsic bandwidth in excess of $90 \mathrm{GHz}$. Such frequencies are not currently attainable due to thermal effects, and remaining device $\mathrm{RC}$ parasitics. If these issues could be minimized along with designs for singlemode operation at extended bias currents, it is believed that significant bandwidth increases could be realized.

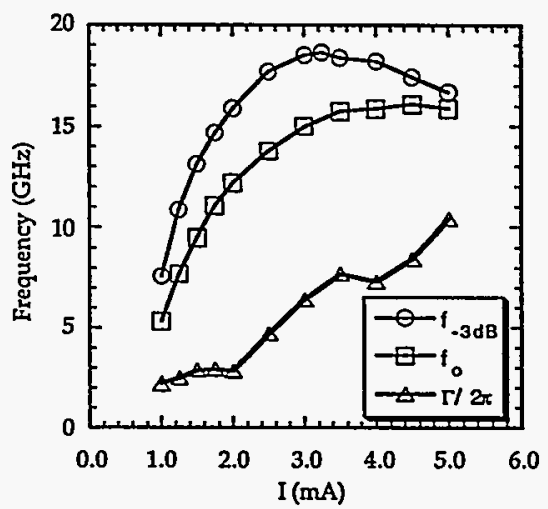

Fig. 7. The cutoff frequency, $f_{-3 d B}$; the extracted relaxation frequency, $f_{o}$; and the extracted resonance width $\Gamma / 2 \pi$ plotted versus bias current.

\section{LARGE SIGNAL OPERATION}

To evaluate large signal operation, two-tone tests and digital measurements were performed. Fig. 8 shows the result of a two-tone test performed at $5 \mathrm{GHz}$ with a device bias current of $3.75 \mathrm{~mA}$. The linear components (at 5 and $5.01 \mathrm{GHz}$ ) and the 3rd order inter-modulation components were seen to both increase at the proper rate $(1 \mathrm{~dB} / \mathrm{dB}$ and $3 \mathrm{~dB} / \mathrm{dB})$. The vertical scale in this plot represents the actual power levels measured on a spectrum analyzer. The scale is relative as the fiber coupling can be arbitrarily adjusted and hence absolute power measurements are difficult. Nevertheless, the intercept from the horizontal axis $(6.5 \mathrm{dBm})$ gives a good indication of suitable drive levels for low distortion analog link applications. The spurious free dynamic range for this fiber optic link is over $40 \mathrm{~dB}$ at optimal bias. This intercept is bias dependent with a measured values of $7 \mathrm{dBm}, \approx 16 \mathrm{dBm}$, and $6.8 \mathrm{dBm}$ at bias currents of $1.25,2.5$ and $3.75 \mathrm{~mA}$, respectively at $5 \mathrm{GHz}$. Measurements at the mid bias range, were difficult due to the small 3rd order component even when driving the device at power levels approaching the $1 \mathrm{~dB}$ compression point (around $-3 \mathrm{dBm}$ ). As expected distortion occurs at either bias extreme.

Fig. 9 shows scope traces of the output light with the VCSEL driven with a $10 \mathrm{GHz}$ square wave and at different bias levels. The top trace shows operation at a point too close to the threshold current, resulting in severe distortion. The middle trace shows operation at an idle current which is 
more suitable, though ringing still occurs due to the limited optical damping at low drive currents. Finally, the lower trace shows operation a $3 \mathrm{~mA}$ bias current which results in a faithful reproduction of the drive signal.

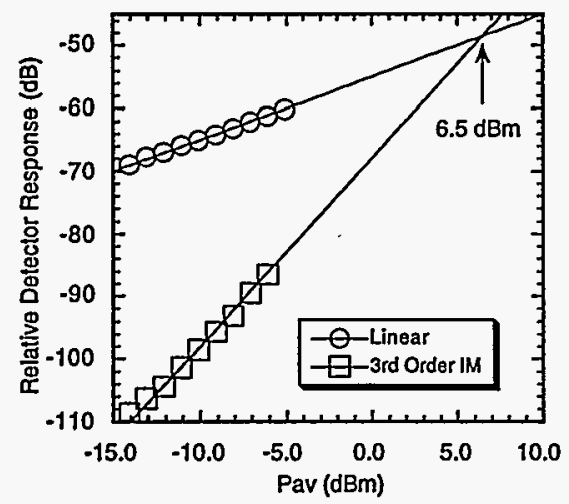

Fig. 8. Measured linear (5.01 GHz) and 3rd order $(5.02 \mathrm{GHz})$ product versus unmatched average input power.

Fig. 10 shows an eye diagram at $10 \mathrm{Gbps}\left(2^{\wedge} 8-1\right.$ sequence) with a reasonable eye width. Part of the noise seen in Fig. 10 is electrical noise caused the measurement system (detector is operated directly into the oscilloscope).
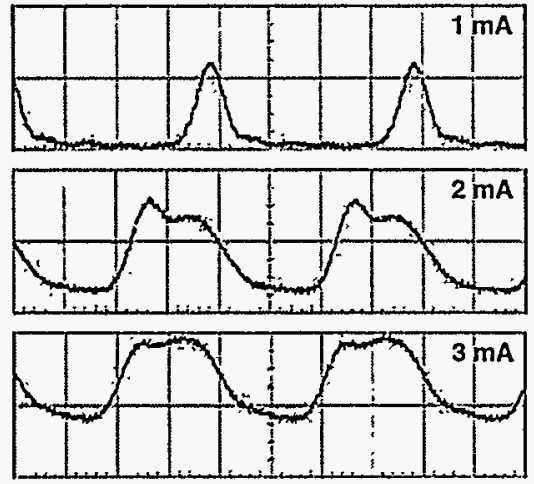

Fig. 9. VCSEL light emission with a $10 \mathrm{Gbps}$ ECL-level square wave excitation at 1,2 , and 3 $\mathrm{mA}$ bias currents. Bottom of scale is no light. Top is VCSEL light level at $4.4 \mathrm{~mA}$ drive.

\section{CONCLUSIONS}

Electrical characterization of a very large bandwidth VCSEL laser was presented. Both small and large signal effects have been investigated. Current designs appear to be useable to bit rate speeds in excess of $10 \mathrm{Gbps}$. The intrinsic speed limit of the device is believed to be significantly higher than present measured extrinsic performance. Future designs with improved thermal management, lower device parasitics, and improved mode confinement are expected to produce bandwidths well within the millimeter wave frequency regime.

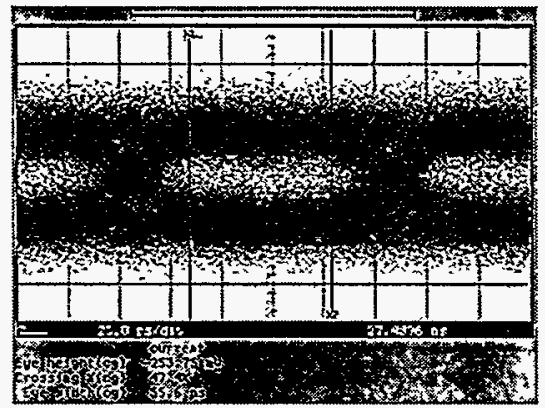

Fig. 10. Eye diagram of a VCSEL driven at $10 \mathrm{Gbps}$ by a $50 \Omega$ impedance ECL-level source. DC bias level was $3 \mathrm{~mA}$.

\section{ACKNOWLEDGMENTS}

The authors thank F. Cajas, J. Banas, J. Figiel, G. Hammons, S. Kilcoyne, and J. Nevers for their technical assistance.

This work was supported by the U. S. Department of Energy under contract \#DE-AC04-94AL85000. Sandia is a multiprogram laboratory operated by the Sandia Corporation, a Lockheed Martin Company, for the United States Department of Energy.

\section{REFERENCES}

[1] K. L. Lear, H. Q. Hou, V. M. Hietala, K. D. Choquette, and R. P. Schneider, Jr., "Engineering highperformance vertical cavity lasers," will be published in the Proceedings of the IEEE, COMMAND '96, Canberra, Australia, Dec. 8-11 1996.

[2] K. L. Lear, and R. P. Schneider, Jr., "Uniparabolic Mirror Grown by Molecular Beam Epitaxy," Appl. Phys. Lett., vol. 62, pp. 1585-1587, 1993.

[3] K. D. Choquette, R. P. Schneider, Jr., K. L. Lear, and K. M. Geib, "Low Threshold Voltage Vertical-Cavity Lasers Fabricated by Selective Oxidation," Electron. Lett., vol. 30, 00. 2043-2044, 1994.

[4] K. L. Lear, K. D. Choquette, R. P. Schneider Jr. , S. P. Kilcoyne, and K. M. Geib, "Selectively oxidized vertical cavity surface emitting lasers with $50 \%$ power conversion efficiency," Electron. Lett., vol. 31, pp. 208-209, 1995. 